\title{
Household income and contraceptive methods among female youth: a cross-sectional study using the Canadian Community Health Survey (2009-2010 and 2013-2014)
}

\author{
Elizabeth Nethery MSc MSM, Laura Schummers ScD, K. Suzanne Maginley MSc, Sheila Dunn MD MSc, \\ Wendy V. Norman MD MHSc
}

Abstract

Background: Low socioeconomic status is one of many barriers that may limit access to family planning services. We aimed to examine the relation between household income and contraceptive methods among female youth in Canada.

Methods: Our study population included sexually active females aged 15-24 who were trying to avoid pregnancy. We used crosssectional data from the 2009-2010 and 2013-2014 cycles of the Canadian Community Health Survey to compare household income and other sociodemographic covariates for those using oral contraceptives, injectable contraceptives, condoms or a dual method (condoms plus oral or injectable contraceptives).

Results: Of female youth at risk for unintended pregnancy, $59.2 \%$ reported using oral contraceptives, $29.0 \%$ used dual methods, $16.8 \%$ used condoms only, $2.5 \%$ used injectable contraceptives and $13.6 \%$ did not use contraception. In multiple regression models, lower annual household income (<\$80 000) was associated with decreased use of oral contraceptives (relative risk [RR] 0.85, 95\% confidence interval $[\mathrm{Cl}]$ 0.80-0.91) and dual methods (RR 0.81, 95\% Cl 0.71-0.91), increased use of condoms (RR 1.36, 95\% Cl 1.11-1.67) and injectable contraceptives (RR 1.69, 95\% Cl 0.98-2.92), and a greater risk of contraceptive nonuse (RR 1.19, 95\% Cl 0.94-1.50).

Interpretation: We found that lower household income was associated with decreased use of oral contraceptives and increased reliance on injectable contraceptives and condoms only. Young, low-income females may face barriers to accessing the full range of contraceptive methods available in Canada. Easier access to affordable contraception may decrease the number of female youth at risk for unintended pregnancy due to financial barriers.

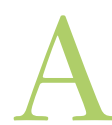
ccess to safe and reliable contraception is critical for reproductive-aged females and their male partners. On average, Canadian females aged 30 years or more spend 3 years trying to conceive, pregnant or immediately post partum; ${ }^{1}$ they spend the remainder of their reproductive years trying to avoid pregnancy. As a public health measure, equitable access to affordable contraception supports healthy spacing between planned pregnancies, reduces the number of high-risk pregnancies ${ }^{2}$ and decreases avoidable health care expenditures associated with unintended pregnancies. ${ }^{3,4}$ An estimated $30 \%-40 \%$ of pregnancies in Canada are unintended ${ }^{1,3}$ and disproportionately affect adolescents and young adults ${ }^{5,6}$ and other vulnerable groups, including recent immigrants, rural residents and those of lower socioeconomic status. ${ }^{7}$ Despite growing evidence of benefits associated with increasing access to contraception, both publicly funded provincial and private health insurance plans often limit access to the full range of contraceptive options available in Canada. There are numerous barriers to contraceptive use in Canada, includ- ing high cost, restricted access to care and limitations in health care providers' knowledge or counselling. ${ }^{8-11}$

Among contraceptives currently available in Canada, the more effective methods ${ }^{1,12}$ are also the most expensive (Table 1) and underused, particularly among vulnerable populations. ${ }^{2}$ Although oral contraceptives are the most commonly used hormonal method in Canada, ${ }^{13}$ over $50 \%$ of youth

Competing interests: Wendy Norman reports grants from the Canadian Institutes of Health Research, Public Health Agency of Canada, and the Michael Smith Foundation for Health Research, and infrastructure support from the Women's Health Research Institute, BC Women's Hospital and Health Centre, Provincial Health Services Authority during the conduct of the study. She is a member of the Board of Directors of the Society of Family Planning. No other competing interests were declared.

This article has been peer reviewed.

Correspondence to: Elizabeth Nethery, elizabeth.nethery@alumni.ubc.ca CMAJ Open 2019. DOI:10.9778/cmajo.20190087 
Table 1: Contraceptive methods available in Canada, 2009-2014, by effectiveness

\begin{tabular}{|c|c|}
\hline Effectiveness; $^{*}$ method & $\begin{array}{c}\text { Cost } \\
\text { estimate† }\end{array}$ \\
\hline Tier $1:<1$ pregnancy per 100 per year & $\$ \$ \$$ \\
\hline \multicolumn{2}{|l|}{$\begin{array}{l}\text { Intrauterine contraceptives (hormonal or } \\
\text { nonhormonal), effective for up to } 5 \mathrm{yr}\end{array}$} \\
\hline Tier 2: 4-12 pregnancies per 100 per year & $\$ \$$ \\
\hline \multicolumn{2}{|l|}{$\begin{array}{l}\text { Injectable contraceptives (depot } \\
\text { medroxyprogesterone acetate), repeated every } \\
3 \text { mo }\end{array}$} \\
\hline $\begin{array}{l}\text { Oral contraceptives, vaginal ring or transdermal } \\
\text { patch, repeated monthly }\end{array}$ & $\$ \$$ \\
\hline \multicolumn{2}{|l|}{ Tier $3: \geq 18$ pregnancies per 100 per year } \\
\hline Male condom & $\$$ \\
\hline Diaphragm + spermicide & $\$ \$$ \\
\hline Female condom & $\$ \$$ \\
\hline Fertility awareness methods/calendar & Free-\$ \\
\hline Withdrawal & Free \\
\hline No method & Free \\
\hline \multicolumn{2}{|c|}{$\begin{array}{l}\text { *Range of effectiveness represents typical use, }{ }^{3,12} \\
\text { †Cost varies because of differences in pharmacy/store discounts, pharmacists' } \\
\text { dispensing fees and supplemental insurance benefits. } \$=\text { least expensive, } \$ \$ \text { = } \\
\text { more expensive, } \$ \$ \text { = most expensive. }\end{array}$} \\
\hline
\end{tabular}

report using condoms only, ${ }^{1}$ which may be due to ease of access (nonprescription, no health care visit required, relatively inexpensive or available free of cost). ${ }^{14}$ Data on intrauterine contraceptives in Canada are not available because nationally representative surveys have not included questions about this method. In a recent qualitative study, Canadian health care providers cited cost as the primary barrier to contraception access nationwide. ${ }^{15}$ In Quebec, where contraception is subsidized, residents report the lowest proportion of unmet contraceptive need compared to other provinces. ${ }^{16}$ Low income and immigrant status are also associated with nonuse of contraceptives. ${ }^{17,18}$ Despite evidence of financial barriers to contraception access, ${ }^{19}$ the relation between income and choice of contraceptive method among young Canadian females is not well understood. The aim of the present study was to investigate the association between household income and contraceptive methods in a nationally representative survey sample of sexually active Canadian females aged 15-24.

\section{Methods}

\section{Data source, design and study population}

In this cross-sectional study, we used public use microdata files from 2 cycles (2009-2010 and 2013-2014) of the Canadian Community Health Survey (CCHS). ${ }^{20}$ The CCHS collects information related to use of health care services, health status and determinants of health in Canada. The survey sample is derived by means of a multistage stratified cluster ran- dom sampling design. Canada-wide response rates were $72.3 \%$ in CCHS 2009-2010 and 66.2\% in CCHS 2013$2014 .{ }^{20,21}$ Further details of CCHS sampling methods are available from Statistics Canada. ${ }^{20,21}$

\section{Analytic sample}

The sample was drawn from CCHS respondents who were asked about contraceptives, which included respondents from all the provinces and territories in these survey cycles aged 15-24. We included those at risk for unintended pregnancy: females who were ever sexually active, were not currently pregnant, had not had a hysterectomy and responded "agree" or "strongly agree" to the statement "It is important to me to avoid getting pregnant right now." Inclusion/exclusion criteria and sample sizes are shown in Figure 1. We coded "don't know," "refusal," "not applicable" and "not stated" responses as missing; the primary analysis used complete cases. Records with missing covariates $(6.5 \%)$ were excluded.

\section{Outcome variables}

For contraceptive users, we determined each respondent's method of contraception based on her response to the question "What is your usual form of birth control?" Respondents could select 1 or more methods from the following 6 options: "the pill, injections, condoms, diaphragm, spermicide or other." Outcome variables were the use of 1 ) any oral contraceptive, 2) injectable contraceptives (depot medroxyprogesterone acetate [DMPA]), 3) nonprescription methods (condoms only, condoms and spermicide, or spermicide only; referred to as condoms-only method [respondents who used condoms and spermicide, or spermicide without condoms accounted for $<0.2 \%]$ ) or 4 ) dual method (condoms plus oral contraceptives or DMPA). As these outcomes were not mutually exclusive, we considered each outcome independently. Any respondents who used the contraceptive patch or ring, intrauterine contraceptives, calendar methods or withdrawal were included in the "other" group. Since the CCHS questionnaire did not distinguish between different contraceptive methods in the "other" group, we could not examine these outcomes (including intrauterine contraceptive use) in this study. We defined nonusers of contraception as those who responded "no" to the question "In the past 12 months, did you and your partner usually use birth control?"

\section{Exposure variable}

Our exposure variable was annual household income of $\$ 80000$ or more (yes/no), derived from the 5-level household income variable provided in the CCHS data sets. The cutpoint for high versus low income was based on the estimated median family income in Canada for 2-parent families with children in 2010 (\$78 800).22

\section{Statistical analysis}

We examined the prevalence of each contraceptive method according to sociodemographic characteristics. We used 


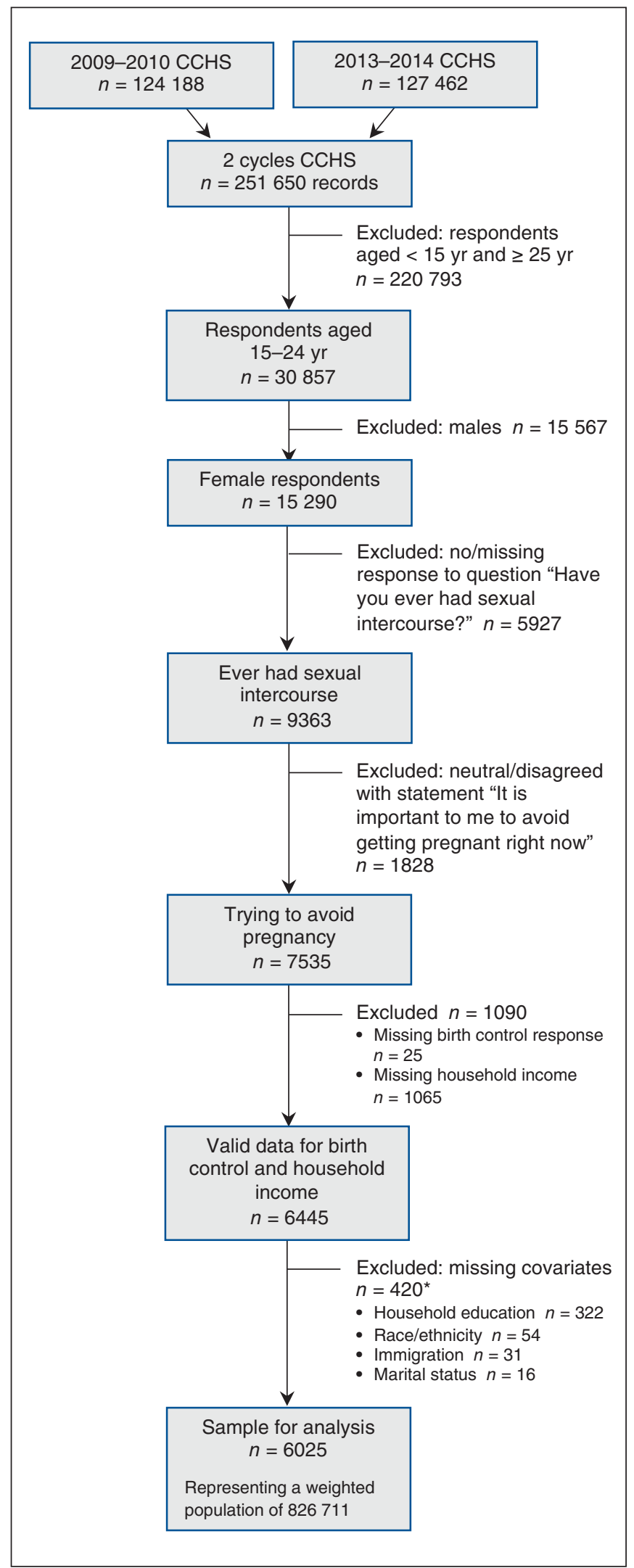

Figure 1: Flow diagram showing selection of sample for analysis. Note: $\mathrm{CCHS}=$ Canadian Community Health Survey. *Numbers total more than 420 because some records were missing more than 1 value. survey weights provided with the CCHS public use data ${ }^{20,21}$ to account for the complex survey design. These enable accurate weighted point estimates but conservative variance estimates compared to cluster and primary sampling units or bootstrap weights. We assessed bivariate associations between each covariate and contraceptive method using a modified $F$ test (with Thomas-Rao modification), ${ }^{23}$ a version of a $\chi^{2}$ test for complex survey data with weights.

We used log binomial regression to estimate risk ratios (RRs) assessing the association between household income and the prevalence of each contraceptive method. For each contraceptive type, we estimated crude and adjusted RRs. The latter adjusted for all potential confounders identified on a priori grounds by means of causal diagrams: age, selfidentified race/ethnicity, highest level of education in the household, northern resident (Yukon Territory, Northwest Territories or Nunavut), student, married and recent immigrant. ${ }^{1,2,8,9,11,13,15,19,24} \mathrm{We}$ conducted analyses using SAS 9.4 (SAS Institute) and R-3.5.1 (R Foundation for Statistical Computing). All analyses applied sampling weights to achieve nationally representative estimates..$^{20}$ Because we pooled 2 CCHS survey cycles, we divided weights by 2 to obtain a representative weighted population across both survey cycles.

\section{Sensitivity analysis}

We explored whether our results were robust to different definitions of household income by fitting additional models, first with the original 5-level household income variable obtained from the CCHS, and then adjusted for household size. To examine whether results may differ in Quebec owing to publicly funded drug benefits, ${ }^{1}$ we estimated RRs separately for Quebec and compared to all other provinces/ territories excluding Quebec. We identified potential variability in estimates (per CCHS cycle) by stratifying analyses for each survey cycle. Finally, we examined the potential impact of missing data in the covariates using multiple imputation with chained equations ${ }^{25}$ to impute missing covariates for 20 data sets using the R package "mice." 26 We considered all possible covariates (with an absolute correlation with the response/imputed variable $>0.1$ ) as predictors for imputation. We repeated survey-weighted logistic regression models among imputed data sets to obtain pooled effect estimates.

\section{Ethics approval}

Ethics approval for using publicly available CCHS data is covered by University of British Columbia policies ${ }^{27}$ and the TriCouncil Policy Statement. ${ }^{28}$

\section{Results}

Of all female survey respondents aged 15-24 $(n=15290$, representing a national population of 2137242 ), 62.4\% reported being sexually active. Our study sample included respondents at risk for unintended pregnancy; this included $48.1 \%$ of all female survey respondents (aged 15-24) and $81.0 \%$ of those 
who were sexually active ( $n=6025$ respondents, representing a national population of 826711 ). Sexual activity differed by age group: $82.0 \%$ of respondents aged $20-24$ had ever been sexually active, compared to $26.4 \%(15-17 \mathrm{yr})$ and $62.6 \%$ (18-19 yr) of younger respondents. Contraceptive nonuse was reported by $13.6 \%$ of the study sample. Rates of nonuse were lowest in Quebec (9.2\%) and highest in the territories (19.4\%). Oral contraceptives were the most popular method (59.2\%), followed by condoms $(47.6 \%)$, other methods $(7.7 \%)$ and injectable DMPA (2.5\%) (Table 2). Over onethird of the study sample (36.5\%) used more than 1 method, typically condoms with oral or injectable contraceptives (29.0\%).

Table 3 shows the number of survey respondents in the study sample, corresponding population estimates (weighted frequencies) and weighted prevalence estimates for each contraceptive method, according to sociodemographic characteristics. The lower-income group reported less use of oral contraceptives than the higher-income group $(53.3 \%$ v. $69.0 \%)$, whereas the inverse was seen for use of DMPA $(3.0 \%$ v. $1.5 \%)$ and condoms only (18.9\% v. $13.3 \%)$. Although DMPA use was low overall, it was slightly higher in the 2 lowest educational attainment groups (4.6\% and $5.0 \%)$ than in the 2 highest educational attainment groups $(2.3 \%$ and $2.0 \%)$. Use of oral contraceptives was more prevalent among white females $(63.2 \%)$ than among those who identified as a visible minority $(43.3 \%)$, but there was no difference by marital status. Patterns of contraceptive use were different in the northern territories compared to the rest of Canada: compared to nonnorthern residents, northern residents reported lower use of oral contraceptives and higher condom-only and DMPA use.

Table 4 presents unadjusted and adjusted RRs for all outcomes, comparing prevalent method-specific use for lower versus higher household income categories. In adjusted models, compared to the higher household income group, lower household income was associated with decreased use of oral contraceptives (RR 0.85, 95\% CI 0.80-0.91) and dual methods (RR 0.81, 95\% CI 0.71-0.91, and increased use of DMPA (RR 1.7, 95\% CI 0.98-2.9) and condoms only (RR 1.4, 95\% CI 1.1-1.7). Adjustment for confounding variables attenuated associations for all outcomes. In models for oral contraceptives and DMPA, adjusting for household education level had the strongest impact on associations. In contrast, estimates for condom-only use were attenuated after adjustment for marital status, ethnicity and immigrant status.

\section{Sensitivity analyses}

We estimated the association of lower versus higher household income on contraceptive outcomes with imputed data for missing covariates (Supplemental Table S1, Appendix 1, available at www.cmajopen.ca/content/7/4/E646/suppl/DC1), and the results were similar to those of our primary analyses for all outcomes (Table 4). Using an income variable adjusted for household size yielded effect estimates with a consistent trend across income categories for all outcomes (Supplemental Tables S2-1 and S2-2, Appendix 1). Stratifying by the

\section{Table 2: Reported usual contraception method(s)}

\begin{tabular}{|c|c|c|}
\hline Method & $\begin{array}{c}\text { Weighted } \\
\text { population } \\
n=826711^{*}\end{array}$ & $\begin{array}{c}\text { Population- } \\
\text { weighted } \\
\text { prevalence } \\
\text { estimate, \%† } \\
(95 \% \mathrm{Cl})\end{array}$ \\
\hline \multicolumn{3}{|l|}{ Survey responsesł } \\
\hline Oral contraceptives§ & 489256 & $59.2(57.2-61.2)$ \\
\hline Condoms & 393446 & $47.6(45.6-49.6)$ \\
\hline Other & 63765 & $7.7(6.6-8.8)$ \\
\hline $\begin{array}{l}\text { Injectable contraceptives } \\
\text { (DMPA)ף }\end{array}$ & 20345 & $2.5(1.9-3.0)$ \\
\hline Diaphragm & 8609 & $1.0(0.7-1.4)$ \\
\hline None & 112510 & $13.6(12.3-15.0)$ \\
\hline \multicolumn{3}{|l|}{ Derived results } \\
\hline $\begin{array}{l}\text { Condoms and/or spermicide } \\
\text { (no other methods } \\
\text { indicated) } \|\end{array}$ & 139044 & $16.8(15.3-18.4)$ \\
\hline$\geq 2$ contraceptive methods & 260803 & $36.5(34.5-38.6)$ \\
\hline $\begin{array}{l}\text { Condoms plus oral } \\
\text { contraceptives or DMPA }\end{array}$ & 240022 & $29.0(27.3-30.8)$ \\
\hline \multicolumn{3}{|c|}{$\begin{array}{l}\text { Note: } \mathrm{Cl}=\text { confidence interval, DMPA = depot medroxyprogesterone acetate. } \\
\text { "Survey sample = } 6025 \text { respondents. } \\
\text { †Survey weighted. } \\
\text { †Respondents could indicate more than } 1 \text { method to the question "What is your } \\
\text { usual method of birth control?" Results for spermicide only not shown owing to } \\
\text { low numbers. } \\
\text { §Primary outcome. } \\
\text { ๆSecondary outcomes: injectable contraceptives and condom/spermicide. }\end{array}$} \\
\hline
\end{tabular}

province of Quebec also yielded similar results for all outcomes (Supplemental Tables S3-1 and S3-2, Appendix 1), with the exception of lower prevalence of nonuse of contraceptives. Estimates were similar after stratification by CCHS cycle.

\section{Interpretation}

Using a nationally representative survey sample, we found that lower household income was associated with lower use of effective contraception methods. Specifically, those with lower household income were $15 \%$ less likely to use oral contraceptives and $19 \%$ less likely to use dual methods (condoms plus oral contraceptives or DMPA) than those with higher household income, after we adjusted for potential confounders. Conversely, they were 69\% more likely to use DMPA and $36 \%$ more likely to use condoms only compared to the higher-income group. These findings are important as there is a paucity of recent nationally representative data on contraceptive patterns, as well as limited information about how household income may be related to choice of contraceptive methods among youth at risk for unintended pregnancy in Canada. ${ }^{2}$ Similar to findings from previous Canadian studies, oral contraceptives and condoms were the predominant methods of contraception, ${ }^{1,13,19}$ and the highest prevalence of oral contraceptive use was among the youngest age group 
Table 3: Number of survey respondents, corresponding population estimates and weighted prevalence estimates for each contraceptive method, by sociodemographic characteristics

\begin{tabular}{|c|c|c|c|c|c|c|}
\hline \multirow[b]{2}{*}{ Covariate } & \multirow{2}{*}{$\begin{array}{l}\text { Survey } \\
\text { sample } \\
n=6025\end{array}$} & \multirow{2}{*}{$\begin{array}{l}\text { Weighted } \\
\text { population, } \\
\text { no. }(\%) \\
n=826711\end{array}$} & \multicolumn{4}{|c|}{ Contraceptive method; weighted prevalence estimate, \% (95\% Cl) } \\
\hline & & & $\begin{array}{c}\text { Oral } \\
\text { contraceptives }\end{array}$ & $\begin{array}{c}\text { Injectable } \\
\text { contraceptives }\end{array}$ & Condom only* & None \\
\hline \multicolumn{7}{|l|}{ Annual household income, $\$$} \\
\hline$<80000$ & 3689 & $516241(62.4)$ & $53.3(50.7-55.9)$ & $3.0(2.2-3.8)$ & $18.9(16.9-21.0)$ & $15.5(13.7-17.3)$ \\
\hline$\geq 80000$ & 2336 & $310470(37.6)$ & $69.0(66.0-71.9)$ & $1.5(0.8-2.2)$ & $13.3(11.0-15.6)$ & $10.5(8.5-12.5)$ \\
\hline \multicolumn{7}{|l|}{ Age, yr } \\
\hline $15-17$ & 1045 & $95467(11.5)$ & $63.7(59.7-67.8)$ & $2.4(1.3-3.6)$ & $15.2(12.2-18.3)$ & $16.3(13.3-19.4)$ \\
\hline $18-19$ & 1325 & $157515(19.1)$ & $59.2(54.8-63.5)$ & $2.6(1.4-3.7)$ & $17.8(14.1-21.5)$ & $14.9(11.6-18.1)$ \\
\hline $20-24$ & 3655 & $573729(69.4)$ & $58.4(55.9-60.9)$ & $2.4(1.7-3.1)$ & $16.8(14.9-18.7)$ & $12.8(11.2-14.5)$ \\
\hline \multicolumn{7}{|l|}{ Race/ethnicity } \\
\hline White & 4910 & $660166(79.9)$ & $63.2(61.0-65.3)$ & $2.3(1.7-2.9)$ & $14.9(13.2-16.6)$ & $11.3(10.0-12.7)$ \\
\hline Visible minority & 1115 & $166545(20.1)$ & $43.3(38.5-48.1)$ & $3.2(1.8-4.6)$ & $24.3(20.5-28.2)$ & $22.6(18.7-26.5)$ \\
\hline \multicolumn{7}{|l|}{ Current student } \\
\hline No & 2618 & $369334(44.7)$ & $52.5(49.4-55.7)$ & $2.8(1.9-3.7)$ & $18.1(15.5-20.6)$ & $17.1(14.8-19.5)$ \\
\hline Yes & 3407 & $457377(55.3)$ & $64.5(62.1-67.0)$ & $2.2(1.5-2.9)$ & $15.8(13.9-17.7)$ & $10.8(9.2-12.3)$ \\
\hline \multicolumn{7}{|l|}{ Married/common-law } \\
\hline No & 5063 & $676199(81.8)$ & $59.9(57.8-62.1)$ & $2.4(1.8-3.0)$ & $17.7(15.9-19.5)$ & $13.2(11.8-14.7)$ \\
\hline Yes & 962 & $150513(18.2)$ & $55.9(50.9-60.9)$ & $2.8(1.4-4.2)$ & $13.0(10.0-15.9)$ & $15.3(11.7-19.0)$ \\
\hline \multicolumn{7}{|l|}{ Recent immigrant† } \\
\hline No & 5871 & $787812(95.3)$ & $60.2(58.2-62.2)$ & $2.5(1.9-3.0)$ & $15.8(14.3-17.4)$ & $13.5(12.1-14.9)$ \\
\hline Yes & 154 & $38899(4.7)$ & $37.9(27.3-48.5)$ & $<2.0$ & $37.0(27.4-46.7)$ & $16.5(10.1-22.9)$ \\
\hline \multicolumn{7}{|l|}{ Highest household education } \\
\hline Less than high school & 284 & 29935 (3.6) & $32.9(23.8-42.1)$ & $4.6(1.8-7.5)$ & $16.6(4.8-28.4)$ & $27.5(19.4-35.7)$ \\
\hline Completed high school & 730 & 89807 (10.9) & $46.0(40.1-51.9)$ & $5.0(2.6-7.4)$ & $20.7(15.7-25.7)$ & $19.6(15.4-23.8)$ \\
\hline Some postsecondary & 502 & $70826(8.6)$ & $55.0(47.7-62.3)$ & $2.3(0.3-4.3)$ & $16.4(11.5-21.3)$ & $17.3(11.9-22.6)$ \\
\hline Completed postsecondary & 4509 & $636143(76.9)$ & $62.7(60.5-65.0)$ & $2.0(1.4-2.6)$ & $16.3(14.6-18.1)$ & $11.7(10.2-13.2)$ \\
\hline \multicolumn{7}{|l|}{ Living arrangement } \\
\hline $\begin{array}{l}\text { Unattached alone/single/ } \\
\text { other }\end{array}$ & 901 & $160085(21.3)$ & $56.9(51.8-62.0)$ & $3.6(2.0-5.1)$ & $19.9(15.8-24.0)$ & $11.0(8.3-13.8)$ \\
\hline With partner or spouse & 525 & 92736 (12.3) & $67.0(61.1-72.9)$ & $2.3(0.4-4.2)$ & $10.9(7.3-14.5)$ & $11.0(6.8-15.1)$ \\
\hline With partner and child & 295 & $35205(4.7)$ & $33.1(23.8-42.4)$ & $3.9(1.0-6.8)$ & $16.8(10.1-23.4)$ & $23.2(15.4-31.1)$ \\
\hline $\begin{array}{l}\text { With own child/ren } \\
\text { (no spouse) }\end{array}$ & 219 & $20809(2.8)$ & 33.7 (24.0-43.5) & $4.1(1.4-6.8)$ & $12.6(6.4-18.7)$ & $28.2(17.9-38.5)$ \\
\hline $\begin{array}{l}\text { Child living with parent(s) or } \\
\text { siblings or both }\end{array}$ & 3579 & $444087(59.0)$ & $63.3(60.8-65.8)$ & $1.7(1.1-2.3)$ & $17.0(14.9-19.1)$ & $12.7(11.0-14.4)$ \\
\hline \multicolumn{7}{|l|}{$\begin{array}{l}\text { Consulted doctor or nurse in } \\
\text { previous } 12 \text { mo }\end{array}$} \\
\hline No & 744 & $104844(12.7)$ & $42.4(36.3-48.5)$ & $1.5(0.4-2.6)$ & $26.8(21.9-31.8)$ & $22.9(17.9-27.8)$ \\
\hline Yes & 5278 & $721490(87.3)$ & $61.6(59.5-63.7)$ & $2.6(2.0-3.2)$ & $15.4(13.7-17.0)$ & $12.3(10.9-13.6)$ \\
\hline \multicolumn{7}{|l|}{ Has family doctor } \\
\hline No & 1132 & $168906(20.5)$ & $48.1(43.2-53.0)$ & $2.0(0.8-3.3)$ & $21.0(17.2-24.8)$ & $18.2(14.5-21.9)$ \\
\hline Yes & 4887 & $656656(79.5)$ & $62.0(59.9-64.2)$ & $2.6(2.0-3.2)$ & $15.7(14.0-17.4)$ & $12.5(11.0-13.9)$ \\
\hline \multicolumn{7}{|l|}{ Northern residentł } \\
\hline No & 5823 & 823779 (99.6) & $59.3(57.3-61.3)$ & $2.4(1.9-3.0)$ & $16.8(15.2-18.4)$ & $13.6(12.2-14.9)$ \\
\hline Yes & 202 & $2933(0.4)$ & $33.9(26.3-41.6)$ & $9.6(4.2-15.0)$ & $22.5(15.4-29.7)$ & $19.4(12.7-26.1)$ \\
\hline \multicolumn{7}{|l|}{ Quebec resident§ } \\
\hline No & 4747 & $619576(74.9)$ & $57.9(55.6-60.2)$ & $2.6(2.0-3.3)$ & $17.2(15.4-19.0)$ & $15.1(13.5-16.7)$ \\
\hline Yes & 1278 & $207135(25.1)$ & $63.1(59.1-67.1)$ & $1.9(0.9-2.9)$ & $15.8(12.8-18.7)$ & $9.2(6.8-11.6)$ \\
\hline \multicolumn{7}{|c|}{$\begin{array}{l}\text { Note: } \mathrm{Cl}=\text { confidence interval. } \\
\text { *Includes those who used only spermicide and/or condoms. } \\
\text { †lmmigrated to Canada within the previous } 10 \text { years. } \\
\text { †Resident of the Yukon Territory, Northwest Territories or Nunavut. } \\
\text { §Quebec has a publicly funded prescription benefit program that includes contraceptive coverage for youth who are not already covered by a private drug plan. }\end{array}$} \\
\hline
\end{tabular}


Table 4: Association of lower versus higher annual household income on contraceptive methods

\begin{tabular}{|c|c|c|c|c|}
\hline \multirow[b]{2}{*}{ Primary outcome } & \multicolumn{2}{|c|}{$\begin{array}{l}\text { Household income; weighted } \\
\text { frequencies }\end{array}$} & \multirow{2}{*}{$\begin{array}{l}\text { Crude RR } \\
(95 \% \mathrm{Cl}) \text { for } \\
\text { lower-income } \\
\text { group }\end{array}$} & \multirow{2}{*}{$\begin{array}{c}\text { Adjusted RR* } \\
(95 \% \mathrm{Cl}) \text { for } \\
\text { lower-income } \\
\text { group }\end{array}$} \\
\hline & $\begin{array}{c}<\$ 80000 \\
n=516241\end{array}$ & $\begin{array}{c}\geq \$ 80000 \\
n=310470\end{array}$ & & \\
\hline Oral contraceptives & 275176 & 214080 & $0.77(0.72-0.83)$ & $0.85(0.80-0.91)$ \\
\hline Injectable contraceptives (DMPA) & 15573 & 4772 & $1.96(1.16-3.32)$ & $1.69(0.98-2.92)$ \\
\hline Condom only & 97682 & 41363 & $1.42(1.16-1.74)$ & $1.36(1.11-1.67)$ \\
\hline Nonusers (no contraceptive method) & 79856 & 32654 & $1.47(1.17-1.84)$ & $1.19(0.94-1.50)$ \\
\hline $\begin{array}{l}\text { Multiple methods: condoms plus oral } \\
\text { contraceptives or DMPA }\end{array}$ & 126256 & 113766 & $0.67(0.59-0.75)$ & $0.81(0.71-0.91)$ \\
\hline
\end{tabular}

(15-17 yr). ${ }^{1,19,29} \mathrm{We}$ also note that the association with income differed for oral contraceptives compared to DMPA or condoms in unadjusted analyses and after we controlled for confounding. This trend was consistent in models using a 5-level income variable adjusted for household size.

Although previous Canadian studies identified greater oral contraceptive use by higher income status, ${ }^{19,29}$ these analyses did not focus on income as the exposure of interest. Our findings suggest that young females from higher-income households may be able to access a broader range of effective contraceptive methods, perhaps because cost is reduced or eliminated as a barrier. ${ }^{15}$ Higher-income families may also have prescription drug benefits to subsidize costs of contraceptives. ${ }^{30}$ Furthermore, young females from higher-income households were also more likely to use multiple contraceptive methods, which provides greater protection against unintended pregnancies than oral contraceptives alone while also reducing the risk of sexually transmitted infections.

Although DMPA use is relatively low in Canada, we found increased use of DMPA among low-income female youth across Canada, with even higher use in the territories. This could be due to unexamined confounders, such as differences in provider counselling, contraceptive access, health insurance or patient preferences. In the United States, DMPA use is higher among certain vulnerable populations, including Indigenous, ${ }^{31}$ racial or ethnic minorities ${ }^{32}$ and those with low income. ${ }^{33,34}$ Although DMPA provides effective contraception and is preferred by some, it has a controversial history, including targeted marketing and provision to vulnerable groups, which may indicate reproductive coercion. ${ }^{35-38}$ Furthermore, the side effects of bone density loss and weight gain ${ }^{39,40}$ may be particularly important for youth. Our findings warrant further examination by means of both qualitative and quantitative methods to elucidate reasons for the differential patterns of use in low-income and northern Canadian populations. Choices about contraceptive use are multifactorial and are affected by a variety of factors, including personal experiences, provider counselling and practice patterns, and access to care.
Our findings signal a need for further research aimed at identifying and eliminating barriers to accessing safe, effective contraception in Canada. ${ }^{41}$ Policies and educational initiatives relating to family planning and prevention of sexually transmitted disease should consider the unique reproductive needs of young females, especially those within vulnerable populations, who are at greatest risk for unintended pregnancy.

\section{Limitations}

Our results are based on self-reported survey data and may be misclassified, which would underestimate our measures of association. We could not include the 2011-2012 CCHS cycle in this study as contraception questions were asked in only 1 province (Ontario) and 2 territories (Northwest Territories and Nunavut), which would limit the generalizability of our results. Furthermore, these CCHS cycles did not include questions about intrauterine contraceptives, which prevented us from extending our analyses to these long-acting, highly effective contraceptive methods. Although newer CCHS cycles (from 2015) do ask about intrauterine contraceptives, questions relating to pregnancy intention have been eliminated. Thus, the newer CCHS surveys cannot directly identify people who need contraception: those at risk for unintended pregnancy. As this group forms the denominator to assess contraception use, it is no longer possible in Canada to use the CCHS to determine the unmet need for contraception or the rates of methods for those who need contraception, nor is there any other nationally representative data source to determine this important information. Because the CCHS asks only those aged 18 years or more about sexual orientation, our sample may include a small number of homosexual females not at risk for unintended pregnancy; however, Pakula $^{42}$ reported that less than 2\% of all 2007-2012 CCHS respondents identified as homosexual. We used household education to represent family socioeconomic status; however, because some respondents were not living with any members of their family, this covariate may be inconsistent as a measure of socioeconomic status. We used household income as a proxy for ability to pay for contraceptives, which may not 
perfectly equate to individual financial status or may be a marker for other unmeasured confounders. Although we controlled for all measured confounders in our adjusted analyses, there may be residual confounding by variables not captured in the CCHS data sets, such as religion, cultural norms, prior adverse events or the use of contraceptives for noncontraceptive purpose (e.g., treatment of irregular menstrual periods, acne, hirsutism). Finally, by nature of the CCHS's crosssectional design, associations between income and contraceptive use cannot be interpreted causally.

\section{Conclusion}

In a nationally representative sample of young Canadian females at risk for unintended pregnancy, we found that lower household income was associated with decreased use of oral contraceptives and increased reliance on injectable contraceptives and condoms only. Our results are consistent with other recent findings that show substantial variations in contraceptive use within Canada, with lower use of more effective contraceptive methods among vulnerable groups. Collectively, these findings suggest that subsidizing or eliminating costs for contraceptives, as called for in a recent position statement by the Canadian Paediatric Society, ${ }^{43}$ could promote equitable access to more effective methods of birth control among low-income youth at risk for unintended pregnancy.

\section{References}

1. Black A, Yang Q, Wen SW, et al. Contraceptive use among Canadian women of reproductive age: results of a national survey. 7 Obstet Gynaecol Can 2009;31: 627-40.

2. Black A, Guilbert E, Costescu D, et al; Society of Obstetricians and Gynaecologists of Canada. Canadian contraception consensus (part 1 of 4). 7 Obstet Gynaecol Can 2015;37:936-42.

3. Canning D, Schultz TP. The economic consequences of reproductive health and family planning. Lancet 2012;380:165-71.

4. Black AY, Guilbert E, Hassan F, et al. The cost of unintended pregnancies in Canada: estimating direct cost, role of imperfect adherence, and the potential impact of increased use of long-acting reversible contraceptives. 7 Obstet Gynaecol Can 2015;37:1086-97.

5. Oulman E, Kim THM, Yunis K, et al. Prevalence and predictors of unintended pregnancy among women: an analysis of the Canadian Maternity Experiences Survey. BMC Pregnancy Childbirth 2015;15:260.

6. Finer LB, Zolna MR. Declines in unintended pregnancy in the United States, 2008-2011. NEngl 7 Med 2016;374:843-52.

7. Parks C, Peipert JF. Eliminating health disparities in unintended pregnancy with long-acting reversible contraception (LARC). Am 7 Obstet Gynecol 2016; 214:681-8.

8. Metcalfe A, Talavlikar R, Du Prey B, et al. Exploring the relationship between socioeconomic factors, method of contraception and unintended pregnancy. Reprod Health 2016;13:28.

9. Dhalla S, Poole G. Determinants of condom use: results of the Canadian Community Health Survey 3.1. Can 7 Public Health 2009;100:299-303

10. Rotermann M, McKay A. Condom use at last sexual intercourse among unmarried, not living common-law 20- to 34-year-old Canadian young adults. Can 7 Hum Sex 2009; 18:75-87.

11. Hall KS, Steinberg J, Cwiak C, et al. Contraception and mental health: a commentary on the evidence and principles for practice. Am 7 Obstet Gynecol 2015; 212:740-6.

12. Sundaram A, Vaughan B, Kost K, et al. Contraceptive failure in the United States: estimates from the 2006-2010 National Survey of Family Growth. Perspect Sex Reprod Health 2017;49:7-16.

13. Norman WV, Leung V, Nuernberger $\mathrm{K}$, et al. Age-related variations in contraceptive method use among Canadian females aged 15-24 years: data from the 2009-2010 Canadian Community Health Survey. Contraception 2013;88:451.

14. Motluk A. Birth control often not covered by Canadian insurers. CMA7 2016; 188:1001-2.

15. Hulme J, Dunn S, Guilbert E, et al. Barriers and facilitators to family planning access in Canada. Healthc Policy 2015;10:48-63.
16. Norman WVV, Leung V, Nuernberger K, et al. Sexually active youth in Canada: regional variations in pregnancy risk, from the 2009-2010 Canadian Community Health Survey. Contraception 2013;88:451.

17. Dunn S, Xiong AQ, Nuernberger K, et al. Non-use of contraception by Canadian youth aged 15 to 24: findings from the 2009-2010 Canadian Community Health Survey. 7 Obstet Gynaecol Can 2019;41:29-37.

18. Aptekman $M$, Rashid $M$, Wright $V$, et al. Unmet contraceptive needs among refugees. Can Fam Physician 2014;60:e613-9.

19. Rotermann M, Dunn S, Black A. Oral contraceptive use among women aged 15 to 49: results from the Canadian Health Measures Survey. Health Rep 2015; 26:21-8.

20. Canadian Community Health Survey - 2014 and 2013-2014 CCHS microdata file user guide. Ottawa: Statistics Canada; 2015.

21. Canadian Community Health Survey - 2010 and 2009-2010 CCHS microdata file user guide. Ottawa: Statistics Canada; 2011.

22. Income of Canadians, 2010. Ottawa: The Daily [Statistics Canada]; 2012 June 18 .

23. Thomas DR, Rao JN. Small-sample comparisons of level and power for simple goodness-of-fit statistics under cluster sampling. 7 Am Stat Assoc 1987;82: 630-6.

24. Castro Martín T. Women's education and fertility: results from 26 demographic and health surveys. Stud Fam Plann 1995;26:187-202.

25. Sterne JAC, White IR, Carlin JB, et al. Multiple imputation for missing data in epidemiological and clinical research: potential and pitfalls. BM7 2009;338: b2393.

26. van Buuren S, Groothuis-Oudshoorn K. mice: multivariate imputation by chained equations in R. 7 Stat Softw 2011;45.

27. University of British Columbia Board of Governors. Policy \# 89: research involving human participants. Vancouver: University of British Columbia; 2012.

28. Canadian Institutes of Health Research, Natural Sciences and Engineering Research Council of Canada, and Social Sciences and Humanities Research Council. Tri-Council policy statement: ethical conduct for research involving humans - TCPS 2 (2018). Ottawa: Secretariat on Responsible Conduct of Research; 2018. Available: www.pre.ethics.gc.ca/eng/policy-politique_tcps2 -eptc2_2018.html (accessed 2019 Oct. 23).

29. Maginley KS. Hormonal contraceptive use in Canada: levels, trends, and determinants among reproductive-aged women in British Colombia [dissertation]. Vancouver: University of British Columbia; 2017.

30. Bolatova T, Law MR. Income-related disparities in private prescription drug coverage in Canada. CMA7 Open 2019;7:E618-23.

31. Urban Indian Health Institute. Reproductive health of urban American Indian and Alaska Native women: examining unintended pregnancy, contraception, sexual history and behavior, and non-voluntary sexual intercourse. Seattle: Seattle Indian Health Board; 2010.

32. Dehlendorf C, Foster DG, de Bocanegra HT, et al. Race, ethnicity and differences in contraception among low-income women: methods received by Family PACT clients, California, 2001-2007. Perspect Sex Reprod Health 2011;43:181-7.

33. Dehlendorf C, Rodriguez MI, Levy K, et al. Disparities in family planning. Am 7 Obstet Gynecol 2010;202:214-20.

34. Ayoola AB, Zandee GL, Johnson E, et al. Contraceptive use among lowincome women living in medically underserved neighborhoods. 7 Obstet Gynecol Neonatal Nurs 2014;43:455-64.

35. Hawaleshka D. A shot in the dark? Macleans 2005 Nov. 28

36. Shea L. Reflections on Depo Provera: contributions to improving drug regulation in Canada. Women Heal Prot 2007;34:1-24.

37. Morgan J. Depo-Provera and the regulation of Indigenous women's reproduction. Burnaby (BC): Simon Fraser University; 2007.

38. Volscho TW. Racism and disparities in women's use of the Depo-Provera injection in the contemporary USA. Crit Sociol 2011;37:673-88.

39. Dianat S, Fox E, Ahrens KA, et al. Side effects and health benefits of depot medroxyprogesterone acetate: a systematic review. Obstet Gynecol 2019;133: 332-41.

40. Black A, Guilbert E, Costescu D, et al. Canadian contraception consensus (part 3 of 4): chapter 8 - progestin-only contraception. 7 Obstet Gynaecol Can 2016;38:279-300.

41. Mitton C, Dionne F, Masucci L, et al. Innovations in health service organization and delivery in northern rural and remote regions: a review of the literature. Int 7 Circumpolar Health 2011;70:460-72.

42. Pakula B. Sexual identity, minority stress, and the mental health of lesbian, gay, isexual, and heterosexual Canadians [dissertation]. Vancouver: University of British Columbia; 2017.

43. Di Meglio G, Yorke E. Universal access to no-cost contraception for youth in Canada (position statement). Paediatr Child Health 2019;24:160-9.

Affiliations: School of Population and Public Health (Nethery, Maginley, Norman) and Department of Family Practice (Schummers, Norman), University of British Columbia, Vancouver, BC; Department of Family and Community Medicine (Dunn), University of Toronto; Women's College Research Institute (Dunn), Toronto, Ont.; Faculty of Public Health \& Policy (Norman), London School of Hygiene \& Tropical Medicine, London, UK 
Contributors: Elizabeth Nethery conceived and designed the project, acquired and analyzed the data and drafted the manuscript. Laura Schummers and Wendy Norman contributed to the study design and data analysis. All of the authors contributed to data interpretation, revised the manuscript critically for important intellectual content, approved the final version to be published and agreed to be accountable for all aspects of the work.

Funding: Elizabeth Nethery is supported by a Vanier Canada Graduate Scholarship. Laura Schummers is supported by a Michael Smith Foundation for Health Research Trainee Award (grant 17934) and a Postdoctoral Health System Impact Fellowship cofunded by the BC Ministry of Health (grant 18183) and the Canadian Institutes for Health Research (grant HI7-160383). Wendy Norman is supported as a Scholar of the Michael Smith Foundation for Health Research (award 2012-5139 HSR) and as an Applied Public
Health Research Chair by the Canadian Institutes of Health Research and the Public Health Agency of Canada (award CPP-329455-107837). Infrastructure support was contributed by the Women's Health Research Institute of the BC Women's Hospital and Health Centre, Provincial Health Services Authority of British Columbia. Sheila Dunn receives research support from the Department of Family and Community Medicine, University of Toronto and the Women's College Research Institute, Toronto.

Acknowledgement: Elizabeth Nethery acknowledges Ehsan Karim, University of British Columbia, who provided guidance on analysis and valuable feedback on early versions of this work.

Supplemental information: For reviewer comments and the original submission of this manuscript, please see www.cmajopen.ca/content/7/4/ E646/suppl/DC1. 